\title{
Forging Partnerships, Experiential Learning, and \\ Community Impact: Capacity Building Matters
}

\section{J. Foster Sawyer ${ }^{1}$, Joanita M. Kant ${ }^{2}$, Jennifer L. Benning ${ }^{1}$, Damon R. Fick ${ }^{3}$ and}

Suzette R. Burckhard ${ }^{4}$

${ }^{1}$ Faculty, South Dakota School of Mines and Technology, Rapid City, South Dakota (e-mail: foster.sawyer@sdsmt.edu)

${ }^{2}$ Research Scientist, ${ }^{4}$ Faculty, South Dakota State University, Brookings, South Dakota (e-mails: Joanita.Kant@sdstate.edu and Suzette.Burckhard@sdstate.edu, respectively)

${ }^{3}$ Faculty, Montana State University, Bozeman, Montana (e-mail: damon.fick@cemontana.edu)

\begin{abstract}
Capacity building can be an important step in working to help more Native American engineering students to earn degrees. The success of educational programs is often evaluated by quantitative data such as matriculation rates. However, we make the case that a broader view of success in the early years of program development with tribal college pre-engineering partner schools may include capacity building as a form of qualitative assessment. If continued funding of such initiatives is withheld because of quantitative assessment alone, coalitions with tribal colleges may not reach their true potential because capacity building is often crucial, and it can take years to mature. In this paper, one co-author interviewed the other three co-authors, using a questionnaire designed to qualitatively assess the successes of the program in regards to capacity building on several levels. Thus, while all the authors are the researchers, three of the co-authors are the research subjects. All are engineers and scientists at the doctoral level. In the resulting essays, the interviewees expressed their opinions about capacity building in their roles in an NSF-sponsored pre-engineering alliance between two mainstream universities and a tribally controlled college. Those interviewed describe their unique qualifications to assess capacity building in this instance. From the perspective of one of the mainstream universities in the alliance, they address categories of capacity building at the following levels: the tribal college; the two participating mainstream universities; the reservation hosting the summer camp; student and faculty participants; tribal, State, and Federal agencies; and STEM disciplines in general. We present common themes in all three essays that reportedly encouraged capacity building, including: (1) building coalitions, (2) engaging in experiential learning, and (3) emphasizing improving the quality of life on Pine Ridge Reservation. We present secondary themes and nonconsensus opinions as additional support for the merits of qualitative assessment.
\end{abstract}

Key words: Tribal colleges, engineering education innovation, capacity building

\section{Introduction}

The National Science Foundation (NSF) funded an ongoing experimental pre-engineering educational innovation project in South Dakota beginning in 2010 that includes a Tribally Controlled College (TCC) on the Pine Ridge Reservation (PRR), and two mainstream state universities, one in Brookings and the other in Rapid City, South Dakota (Fig. 1). The project is 
known as OSSPEEC, an acronym for Oglala Lakota College, South Dakota State University, South Dakota School of Mines and Technology Pre-Engineering Education Collaborative. NSF funded similar pre-engineering education collaborative (PEEC) programs in North Dakota, Wisconsin, and Hawaii ${ }^{1}$ (Boyer 2012).

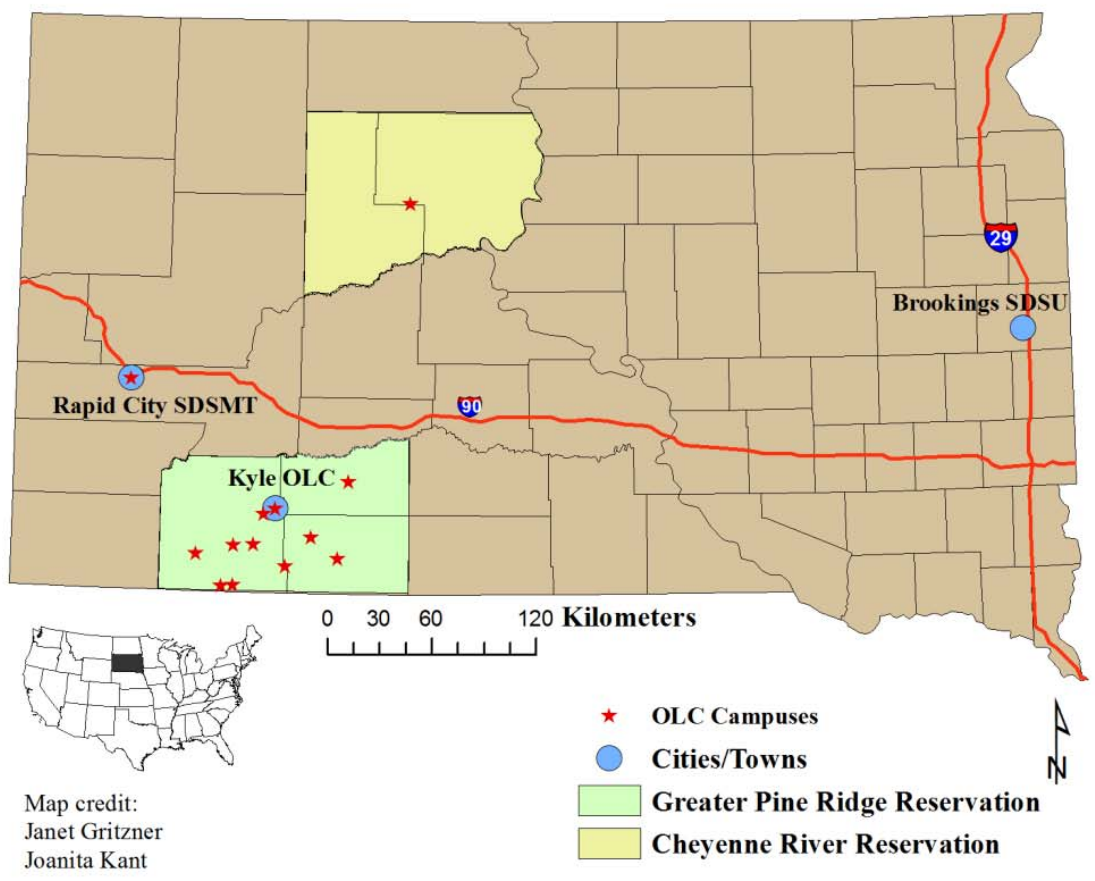

Figure 1. The three collaborating schools in South Dakota within OSSPEEC include SDSMT in Rapid City, OLC with 13 campuses (including one in Rapid City), and SDSU in Brookings.

Within OSSPEEC, the overall goals are to bring engineering curricula to OLC through collaborations with mainstream universities, where OLC graduates may matriculate to earn BS degrees, and to engage Native American students in project-based service learning as a means to increase participation of this underrepresented group in engineering fields. Curriculum articulation agreements between OSSPEEC schools also are important to the program for matriculation.

The OSSPEEC program includes summer service-learning projects, which begin with a weeklong kick-off of presentations and coordination with faculty, students, tribal agency representatives, community leaders from the PRR, and other stakeholders with an interest in the 
program. A primary goal is to design summer Research Experiences for Undergraduates (REUs) that provide meaningful benefits to PRR and that promote positive interaction between reservation residents and students in the program. Following kick-off week activities, students select summer projects, including service-learning and field based research, designed to relate to concerns and sentiments previously articulated by the community, particularly OLC and Oglala Sioux Tribe (OST) governmental and non-governmental agencies ${ }^{2}$ (Figs. 2-3). Later in the summer schedule, student participants prepare and present posters based on OSSPEEC projects at symposiums, such as a state-wide South Dakota Experimental Program to Stimulate Competitive Research (SD EPSCoR) symposium³ in 2014 in Pierre, South Dakota.

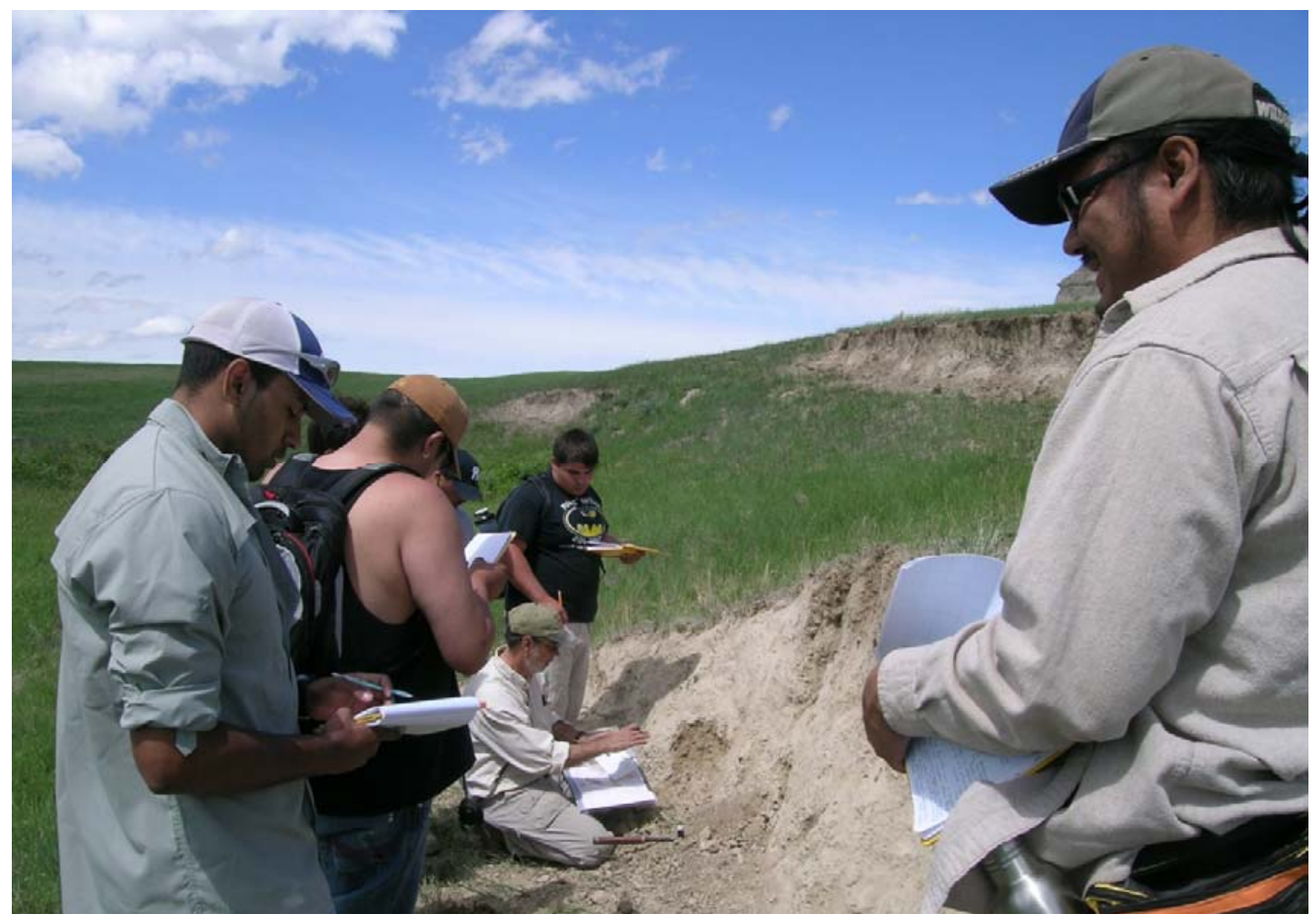

Figure 2. Foster Sawyer (seated), SDSMT faculty, explains aspects of geological mapping to OLC, SDSU, and SDSMT student interns and faculty during summer camp 2012 on PRR. James Sanovia (right), OLC faculty, helps supervise students and increases his knowledge of local geology. 


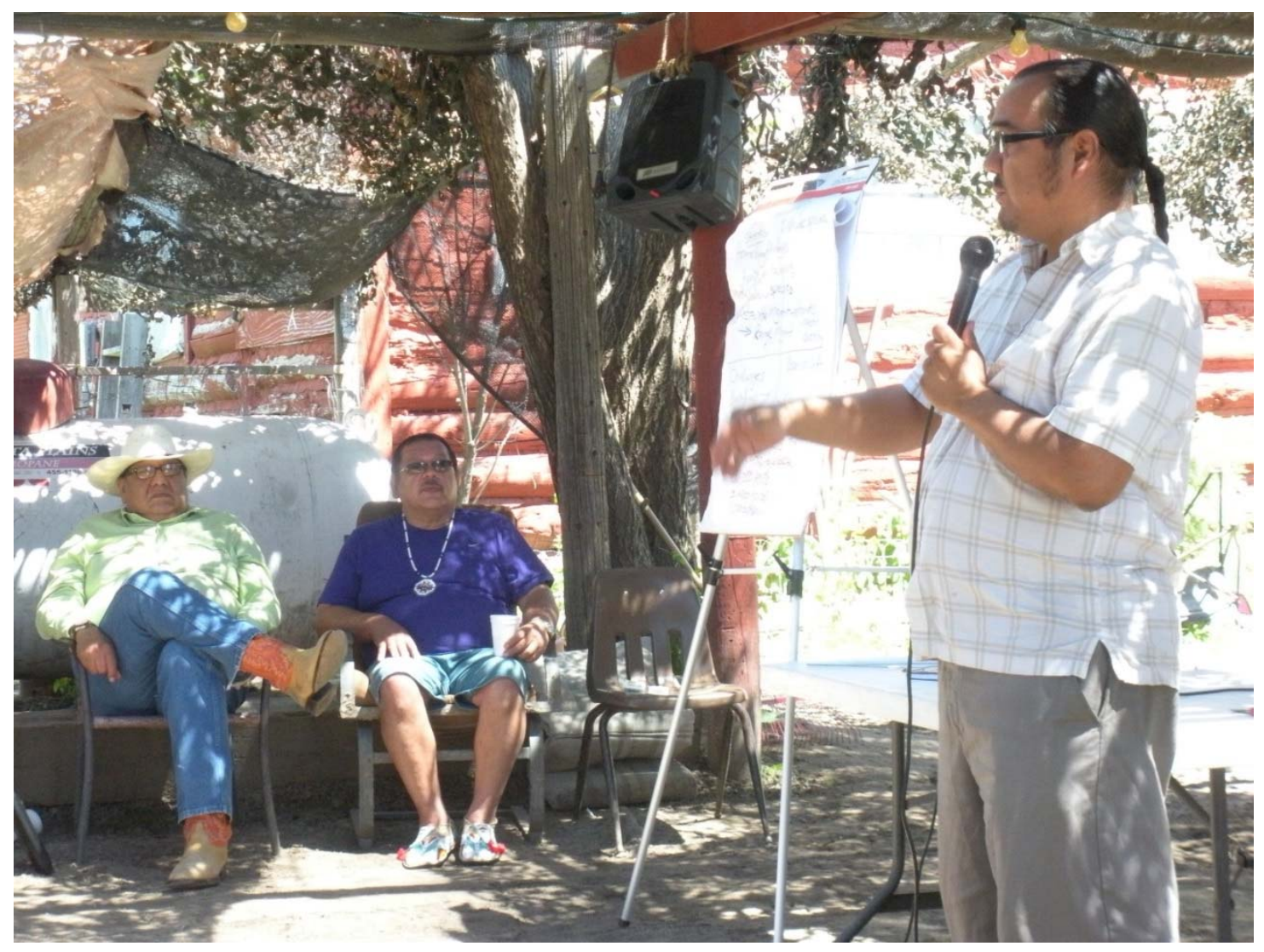

Figure 3. James Sanovia (standing at right), OLC faculty, addresses community leaders, tribal agency representatives, students, and faculty during the 2014 kick-off activities. Seated are tribal community leaders Jhon Goes In Center (left) and Wilmer Mesteth (center).

It is important for all stakeholders in OSSPEEC, that participants produce adequate numbers of students who achieve the goals of the project. We make the case in this paper that capacity building is a means to that end, an important precursor to achieving those numbers. Capacity building deserves more attention in evaluating the success of collaborations between mainline universities and TCCs as noted by Boyer ${ }^{1}$.

A review of the literature revealed several articles about OSSPEEC and other PEEC or PEEClike projects, particularly those from South Dakota and North Dakota ${ }^{1,4-22}$. In addition, we found many useful articles about outcomes generally related to experiential learning, particularly service-learning in STEM fields ${ }^{23-28}$.

\section{Methodology}

Our method of assessing the OSSPEEC program is qualitative and constructivist, after Lord et al., $2005^{29}$ based on Denzin, $1997^{30}$ and Kemmis \& Taggart, $2005^{31}$. Our goal is to develop insights into why capacity building through OSSPEEC summer camps is essential in order to achieve long term success for the task at hand: helping Native American students succeed in 
engineering education. While all co-authors are the researchers in this article, within the method, three of the five researchers and co-authors are also the research subjects. We present consensus and non-consensus opinions extracted from their three essays that began with interviews conducted by co-author Kant. Personal opinions represent their perspectives at SDSMT, using the research instrument in Figure 4. Through interpretation of the essays, we extracted quotations representing three dominant and consensus themes, and we present our results under those three headings, followed by non-consensus views.

\section{CATEGORIES OF CAPACITY BUILDING CONCERNING OSSPEEC SUMMER CAMP FROM THE PERSPECTIVE OF SDSMT}

1. Write a biography as the introductory part of your essay. It will be used to briefly describe why you are uniquely qualified to comment on the topic of capacity building through OSSPEEC summer camp experiences.

2. Comment on the following (A-I), in order to produce an essay explaining how we built capacity for each of the following through OSSPEEC summer camp experiences:
A. OLC as an institution
B. Pine Ridge Reservation
C. SDSU as an institution
D. SDSMT as an institution
E. Undergraduate students
F. Graduate students
G. Faculty and staff
H. Governmental agencies
I. Stem disciplines in general

Figure 4. Research instrument to produce essays.

\section{Subjects of the Research}

The three research subjects are or formerly were faculty members at SDSMT with key roles in OSSPEEC. Each wrote an essay reflecting on the value of capacity building within OSSPEEC summer camps. They include Drs. J. Foster Sawyer, Jennifer L. Benning, and Damon R. Fick. 
The first research subject, J. Foster Sawyer, serves as the Principal Investigator (PI) for the SDSMT component of OSSPEEC, and served in that role since the project's inception in September 2010. He works as faculty in the Department of Geology \& Geological Engineering at SDSMT with about 230 undergraduate and graduate students. The second research subject, Jennifer L. Benning, served since 2011 as a Co-PI and as a faculty collaborator within OSSPEEC, including summer camps. Benning's areas of expertise include indoor air quality and other fields related to sustainable housing. Through her experience and professional contacts she helped to forge strong working relationships between OSSPEEC students and faculty and ongoing sustainable housing research and development efforts on the PRR. The third research subject, Damon R. Fick, began his involvement with OSSPEEC in 2011 as a Co-PI. He mentored and advised five Native American students (two from SDSMT, three from OLC) on projects related to wind energy; the planning and design of the restoration of a veterans' memorial wall in Wanblee, South Dakota; structural testing of friction stir-processed metallic materials; and construction materials testing. He also integrated two of these projects into the Back-to-the Future program, an NSF funded REU held at SDSMT. Additional information on the background and qualifications of the research subjects is presented in Appendix A.

\section{Capacity Building: Recurring Themes}

Three recurring and consensus themes emerged when we analyzed the opinions of the research subjects as they reflected in their essays about the role of OSSPEEC summer camps in capacity building to meet the objective of bringing engineering to Native American students. Those themes included (1) coalition-building, (2) engaging in experiential learning, and (3) emphasizing improving the quality of life on PRR. Some comments fit more than one theme, and we made judgments about where they best fit. We selected all of the following quotations from the essays of the research subjects, two faculty members and one former faculty member from SDSMT, all with key roles in OSSPEEC. We present them in the following order, attributing each to its author by tagging each comment with italicized initials: J. Foster Sawyer $(J F S)$, PI; Jennifer L. Benning (JLB), researcher and field supervisor; and Damon R. Fick (DRF), researcher and field supervisor from 2011 to 2013.

Each research subject brings to his or her essay different perspectives because of their varying experiences at OSSPEEC summer camps. They agree, however, that three basic themes dominate their essays when viewed collectively. They believe that OSSPEEC summer camps build capacity as an important measure of success in the early years of this pre-engineering educational experiment. They are passionate about what OSSPEEC summer camps bring to the task, and they are proud of their accomplishments in which they find personal satisfaction.

\section{Coalition-building}

Coalition building includes efforts to integrate curricula, faculty, students, and infrastructure among the three participating institutions to achieve the overall goals of the program. Following are specific components of coalition building from the individual perspectives of the three research subjects.

- The scientific and engineering characteristics of our OSSPEEC summer research projects reflect the interests and backgrounds of participating faculty, and consist primarily of 
water quality and quantity investigations, geologic mapping, and a variety of topics related to sustainability of natural resources and development practices. During the most recent grant year (2013-3014), we added a mechanical engineering faculty member who has complemented the program through the addition of exciting topics of research such as unmanned aerial vehicles (UAVs), solar powered baja vehicles, and sustainable greenhouse design (JFS).

- Some of the capacity building at OLC involved laboratory renovations there. In addition, equipment was given or loaned to OLC through the OSSPEEC alliance. For example, OLC obtained gauge housing equipment, stream probes (multi analysis tools), supplies, and lab laboratory gear. OSSPEEC also helped to build OLC capacity through enhanced classes for credit and through research activities (JFS).

- I helped teach several classes as part of the summer camp experience, primarily Introduction to Engineering I and II, making possible OLC access to a broader range of faculty experience. Because of curriculum articulation agreements between collaborating OSSPEEC schools, OLC students are assured that their course work at OLC will transfer to SDSMT and SDSU. OLC's He Sapa campus in Rapid City creates more camaraderie between the two schools (JFS).

- $\quad$ OSSPEEC provides a setting where SDSMT has professors and graduate students conducting research projects on PRR, along with undergraduate students from all three participating schools. That provides OLC students and faculty with opportunities to benefit from those experiences, and faculty from SDSMT benefit from working with them as well which continues to create a stronger alliance (JFS).

- The summer camp experience increased relationship-building between faculty and students from the three participating schools. There is a social aspect within OSSPEEC, including field trips to the Black Hills, pot-luck lunches, and outreach activities, among others. Such activities enhance the fieldwork experiences for OLC students and faculty, and for everyone involved from other schools (JFS).

- Our participation helps SDSMT meet some important goals of our strategic plan, including student diversity and networking with a variety of agencies and organizations and other colleges and universities. The curriculum articulation agreements between the three collaborating schools help by ensuring that credits transfer (JFS).

- There is value in undergraduate students communicating with students from other schools and in realizing that they are friendly. The alliance created by OSSPEEC helps to remove barriers for both students and faculty (JFS).

- Within OSSPEEC, three graduate students earned advanced degrees. They experienced interaction with undergraduate students and faculty through project-based service learning, gaining invaluable experience in the management of people and fieldwork logistics. Because of OSSPEEC, they had the opportunity to conduct funded research in a 
reservation setting with field crews of undergraduates from participating schools. That created networking and built relationships with tremendous future potential (JFS).

- OSSPEEC helps to build capacity for faculty from all three participating schools. It is a great opportunity to conduct research on the reservation, and the faculty interaction increases the possibility of publishing the results, a topic of great interest to faculty everywhere. Relationship building, networking, and increased diversity benefitted all faculty involved in OSSPEEC. Participation also provided professional development opportunities, such as attendance at professional conferences and participation in local poster sessions (JFS).

- In 2012, I co-taught the Introduction to Engineering summer course offered through OLC as a part of this program. I incorporated a hands-on sustainability educational module in the OLC offering that is one of the same exercises our freshman Civil and Environmental Engineering students perform at SDSM\&T, thus aligning courses and expectations ( $J L B)$.

- We are collaborating on sustainable housing research with Colorado University at Boulder. We are involving OLC students in air quality, energy, and climate monitoring. Students from SDSMT and OLC used air quality equipment already in place, but unused, at OLC. We helped bring back their ability to use existing equipment from their inventory. In that way, we restored and increased their capacity to conduct environmental research. We saw the importance of collaboration and networking (JLB).

- Because of the many OSSPEEC collaborations, researchers within the project addressed topics such as protection of water resources and community outreach (JLB).

- It has been important for SDSU to become involved with other stakeholders through OSSPEEC. They have built capacity through such outreach as part of their Land Grant school mission $(J L B)$.

- We advised an SDSM\&T senior design team based on a request from OLC for sustainable food production design. As a result, a multidisciplinary team of engineers worked on the design of a greenhouse. Mainstream SDSMT students began the work, which required that they learn about cultural differences in order to include stakeholder participation in the design process. They learned about Lakota culture and challenged some of their long-held assumptions $(J L B)$.

- The relationships we built and are building with OLC and the OST allow stakeholder participation in research and design. We receive input from the community through these collaborations, and then we adjust our research and design to incorporate stakeholder needs $(J L B)$. With help from many of the summer interns in PEEC, I coordinated the creation of a construction materials laboratory in OLC's Math and Science Building in 2012. We purchased soil and concrete materials test equipment and moved a load frame from SDSMT to OLC. We delivered the laboratory component of the new course Engineering 202, Construction Materials with this equipment. As part of this course, I administered certification exams from the American Concrete Institute (ACI) (DRF). 
- OLC developed capacity in the area of teaching - through collaborative teaching opportunities with faculty at SDSMT and SDSU. OLC faculty acted as students, themselves, in many cases and developed the expertise required to deliver new courses to students at OLC $(D R F)$.

- SDSU's PEEC capacity is built around expanding the area and community of Native American students their programs serve. Developing relationships with educators, reservations, and students on the western side of the state is invaluable for their success $(D R F)$.

- SDSMT built increased institutional capacity during OSSPEEC summer camps through the integration of existing Native American Initiatives, in particular, the coordination of Research Experiences for Undergraduates (REU), Tiospaye programs, and summer outreach activities (DRF).

- Graduate students build the capacity of working in a leadership role on their own summer projects while guiding, teaching, and helping undergraduate students. We built capacity with graduate students through coordination of summer events, projects, and group activities (DRF).

- By working closely with students from OLC, SDSMT, and SDSU on their summer projects, faculty at all three institutions built capacity through mentoring students. Understanding the challenges facing students broadened many perspectives of studentfaculty relationships $(D R F)$.

\section{Engaging in Experiential Learning}

One goal of the OSSPEEC program is to incorporate hands-on, reservation based, service learning projects that engage the participants with community members of the PRR and vertically integrate experiential, research based learning into student curricula at the freshman and sophomore levels. This goal is achieved through a number of research topics and teams that are organized each summer to fit faculty and student interest and expertise. Drs. Sawyer, Benning, and Fick all led different research efforts, and their comments with respect to experiential learning are as follows.

- Project based service-learning, such as the Wanblee Veterans' Wall, benefits the people of PRR, and that helps students to internalize the value of professional ethics (JFS).

- Concerning the local residents of PRR in general, OSSPEEC built capacity through making available research information and service projects that did not exist before (JFS).

- I worked with OSSPEEC students on various service-learning projects, including surface water quality monitoring, integrating OSSPEEC students into efforts by the OST EPP towards water resource protection, indoor air quality monitoring to support sustainable 
housing research in support of efforts by the Native American Sustainable Housing Initiative (NASHI, centered at the University of Colorado, Boulder), and, most recently, design for sustainable food production on PRR (JLB).

- Their participation in experiential learning benefitted SDSU and their engineering and science programs. Such experiences built capacity that has potential for even more benefits in the future $(J L B)$.

- Students working in teams or groups built capacity by supporting each other or providing help to one another when working on various community service or research projects $(D R F)$.

\section{Emphasizing Improving the Quality of Life on Pine Ridge Reservation}

A central theme of the OSSPEEC program is that service learning projects inherently benefit the residents of PRR while simultaneously benefitting the students in numerous ways, and that science, technology, engineering, and math (STEM) can have powerful impacts on quality of life. Comments pertaining to the impacts on quality of life that have resulted from the program are as follows.

- Data from a variety of OSSPEEC projects makes it possible for tribal governmental agencies to manage their resources better to improve the quality of life on PRR. That helps all PRR residents if we can help conserve their water quality (JFS).

- I am learning about a Native American community (PRR) in general, something that is important to me in the way of personal growth and development. The potential benefit to the local community is also meaningful for me, personally (JFS).

- Tribal government benefitted substantially, including the tribe's Natural Resources Regulatory Agency (NRRA), through an informal partnership where we work to define or characterize natural resources so that they can better manage them. Our work is of value to them. Some examples of projects with OSSPEEC involvement that are of benefit to PRR tribal government include the Thunder Valley sustainable housing initiative and our mapping of the hydrology of PRR and nearby areas (JFS).

- The state of South Dakota also generally benefits from the water quality data. On the Federal level, the Environmental Protection Agency (EPA) benefits because they want the tribe to monitor the water. In these ways, OSSPEEC encourages capacity building (JFS).

- I recall an SDSMT Native American student in a structural engineering program. He worked in water resources for a summer, and the experience proved beneficial for him, too. He was not necessarily going back to the reservation to work, but he was impressed with the importance of water quality. These kinds of exposures to a variety of experiences help increase his deep knowledge. It makes him consider another perspective: how his interests relate to a bigger picture (JLB). 
- For all undergraduate students in OSSPEEC, they get to see some real and applied engineering work. They are more motivated in their degrees. They can see the potential benefits of their degrees for their communities $(J L B)$

- Tribal organizations need more engineers on reservations for the benefit of projects that improve lives, such as developing sustainable housing and protecting water resources. Hopefully, at some point, the students we work with could become future managers on these types of projects. (JLB).

- All governmental agencies should care, because, for example, what happens to water resources on the reservation affects other places, off the reservation. Another example is that achieving sustainable, healthy, and affordable housing could mean less need for support of those in poverty $(J L B)$.

- Most recently, my involvement with PEEC relates to incorporating a sustainable housing development on the PRR into the Civil Engineering Capstone Design course at SDSMT. This project is a collaboration between the University of Colorado, Boulder, and the Thunder Valley Community Development Corporation. My first advisee in PEEC completed this course to graduate with a Bachelor's degree in Civil Engineering from SDSMT in May 2013 (DRF).

- The Pine Ridge Reservation developed capacity through their approach to addressing science and engineering-related concerns on PRR. Working with students from all institutions, Tribal agencies have learned with students in the areas of ecology, water quality, biology, and transportation (DRF).

- By understanding the relationships, interests, and experiences of Native American students, STEM disciplines build capacity by implementing best educational practices to recruit and retain these students $(D R F)$.

\section{Non-consensus Opinions}

While three major themes represent consensus opinions, we also extracted non-consensus opinions. Those included increasing awareness that recruitment of Native American engineers needs to begin much earlier in the educational process, certainly by high school. Another nonconsensus opinion included recognizing the value of working in another culture and the value of undergraduate student research experiences that are not usually available to students in their freshman and sophomore years.

\section{Conclusions}

Three faculty or former faculty members from SDSMT presented their qualifications to comment on the value of OSSPEEC summer camps in building capacity to help produce more Native American engineers. OSSPEEC is an NSF funded educational experiment between a TCC and two mainstream universities. The research subjects played various roles within the project, as PI 
or Co-PIs, faculty, field research project leaders, and mentors. They presented their unique perspectives. We extracted and present consensus and non-consensus opinions from their essays in which they reflect on their experiences. Three major themes emerged that encouraged capacity building for meeting the task set for OSSPEEC summer camps including: (1) coalition-building, (2) engaging in experiential learning, and (3) emphasizing the improvement of the quality of life on PRR. We also acknowledged non-consensus opinions, although there were few. We agreed that capacity building is an important qualitative measure of success, particularly in the early years of building coalitions between mainstream universities and TCCs. While numbers of students who meet the task matter, capacity building is essential in setting the stage for success.

\section{Acknowledgments}

This material is based upon work supported by the National Science Foundation under Grant No. 1037797 which the authors gratefully acknowledge. We thank OLC and the OST for hosting this project on PRR. We thank Professor Emeritus Janet Gritzner, Department of Geography, SDSU, for help with the map shown in Figure 1.

\section{Bibliography}

1. Boyer, P. 2012. Bringing engineering to Indians: A status report on the National Science Foundation's PreEngineering Education Collaborative. Washington, D. C.: NSF. Retrieved March 5, 2014 www.swc.tc/Scott\%20Morgan/Bringing_Engeering_to_Indians.pdf.

2. Oyate Omniciye Consortium and Steering Committee. The Official Sustainable Development Plan of the Oglala Sioux Tribe, May 21, 2012, 1-269. Retrieved June 22, 2014 http://www.oglalalakotaplan.org/wpcontent/uploads/2013/11/Oyate-Omniciye-Final-.pdf .

3. SD EPSCoR: Research, Education, Economic Development website. 2014. 2014 South Dakota Undergraduate Research Symposium. Retrieved June 30, 2014 http://www.sdepscor.org/event/reu-research-symposium/.

4. Davis, C., Padmanabhan, G., Pieri, R., Lin, W., Patterson, F., \& Cobb, S. (2000). The Genesis of a MultiInstitutional Collaborative Educational Initiative Proposal. Proceedings of the ASEE Annual Conference, Albuquerque, New Mexico, June 2000.

5. Fick, D.R., Sawyer, J.F., \&Tinant, C.J. 2013. Retention and Recruitment as Part of a Pre-Engineering Education Collaborative. Proceedings of the ASEE Rocky Mountain Section Regional Conference, Pueblo, Colorado, March 2013.

6. Fick, D.R., Gribb, M. M., \& Tinant, C.J. 2013. The Impact of Project-Based Service Learning in a Native American Community on Student Performance in Civil Engineering Capstone Design. Frontiers in Education. Proceedings of the $43^{\text {rd }}$ Annual Conference, IEEE, Oklahoma City, Oklahoma, October 2013.

7. Fick, D.R., Sawyer, J. F., Tinant, C. J., \& Berdanier, B.W. Civil and Geological Engineering Service-Learning Projects As Part of a Pre-Engineering Education Collaborative. Proceedings of the $42^{\text {nd }}$ ASEE/IEEE Frontiers in Education Conference, Seattle, Washington, October 2012.

8. Hartman, K., Bennett, B., Colombe, L., Davis, C., Guinn, J., Halvorson, G., Kubisiak, S., LaVallie, A., Lohnes, J., Long Feather, C., Longie, E., Lin, W., Marxen, H., Padmanabhan, G., Pieri, R., Perkins, W., \& Pfahl, M. 2007. 
A North Dakota Tribal College Faculty Model: Guiding Undergraduate Student Research in Science, Technology, Engineering, and Math. North Dakota Tribal College Faculty, North Dakota [State]University Faculty, \& North Dakota Association of Tribal Colleges, n.p., 11-27. Retrieved June 27, 2014

http://www.ndepscor.nodak.edu/NATURE/Documents/NDTribalCollegeFacultyResearchModel_8-30-07_final.pdf.

9. Kant, J. M., Burckhard, S. R., Min, K., \& Kilts, W. K. Increasing Diversity in Engineering: Capacity Building Matters. The 2014 ASEE North Midwest Section Conference, Iowa City, Iowa, October 2014 (in review).

10. LaVallie, A., Khan, E., \& Padmanabhan, G. Community-Relevant Research for TCC STEM Student Retention, Proceedings of the ASEE Annual Conference, Atlanta, Georgia, June 2013.

11. LaVallie, A., Khan, E., \& Padmanabham, G. Impact of a Research Experience Program on North Dakota Tribal College STEM Student Retention. Proceedings ASEE North Midwest Section Conference, Fargo, North Dakota, October 2013. Retrieved April 5, 2014 http://whavenlabs.com/ASEEConference/html/papers/ASEE-NMWSC20130004.pdf.

12. Lin W., Padmanabhan, G., Pieri, R., \& Patterson, F. Experiences with and Lessons Learned in a STEM Summer Camp for Tribal College Students. Proceedings of the ASEE Annual Conference and Exposition, Honolulu, Hawaii, June 2007.

13. Lin, W., Padmanabhan, G., Pryor, S., \& Wiesenborn, D. Introducing Native American Community College Students to Engineering through Hands-On Exploratory Projects. Proceedings of the ASEE Annual Conference and Exposition, Honolulu, Hawaii, June 2007.

14. Mehta, Y., Jansson, P. M., \& Dorland, D. Learning through the Design of a Fish Hatchery for a Community on the Cheyenne River Reservation - An EWB [Engineers-Without-Borders] Service-Learning Project. Proceedings of the ASEE Annual Conference and Exposition, Honolulu, Hawaii, June 2007. Retrieved April 10, 2014 http://www.icee.usm.edu/icee/conferences/asee2007/authors/M.html.

15. Padmanabhan, G., Lin, W., Pieri, R., Patterson, F., \& Cobb, S. Strengthening Native Pathways to Science and Engineering Education. Proceedings of the ASEE Annual Conference, Montreal, Canada, June 2002.

16. Padmanabhan, G., Lin W., Pieri, R., Patterson, F., Cobb, S. \& Davis, C. A University--Tribal Colleges--High Schools Partnership to Increase Native American College Graduates in Mathematics, Science, and Engineering. Proceedings of the ASEE Annual Conference, Salt Lake City, Utah, June 2004.

17. Padmanabhan, G., Lin, W., Pieri, R., Patterson, F., \& Khan, E. A Weekend STEM Enrichment Program for Tribal High School Teachers and Students. Proceedings of the ASEE Annual Conference and Exposition, Chicago, Illinois, June 2006.

18. Padmanabhan, G. and Davis, C. A. Undergraduate Research Experience: A Collaborative Model for Tribal Community College Students, GC 2008-133, 7th Global Colloquium on Engineering Education, Cape Town, South Africa, October 2008.

19. Padmanabhan, G. \& Davis, C. A. Collaborative Research-Mentoring for Tribal College Students. Proceedings of the ASEE Annual Conference, Vancouver, B. C., Canada, June 2011.

20. Padmanabhan, G., Pieri, R. V., \& Davis, C. A Unique University-Tribal College Collaboration to Strengthen Native American Pathways to STEM Education. Proceedings of the ASEE Annual Conference and Exposition, Vancouver, B. C., Canada, June 2011.

21. Padmanabhan, G., De Saram, D. D., Schanandore, T. C., Schanandore, J., \& Pieri, R. V. A Surveying Course as Summer Experience for a Tribal College Pre-Engineering Program. Proceedings of the ASEE Annual Conference \& Exposition, Atlanta, Georgia, June 2013. 
22. Tinant, C. J., Kant, J. M., LaGarry, H. E., Sanovia, J. J. \& Burckhard, S. R. Building Trust, Experiential Learning, and the Importance of Sovereignty: Capacity Building in Pre-Engineering Education - A Tribally Controlled College Perspective. The 2014 ASEE North Midwest Section Conference, Iowa City, Iowa, October 2014 (in review).

23. Barrington, L., \& Duffy, J. Attracting Underrepresented Groups to Engineering with Service-Learning. Proceedings of the ASEE International Exposition and Conference, Honolulu, Hawaii, June 2007.

24. Bringle, R. G., Hatcher, J. A., \& Muthiah, R. N. 2010. The Role of Service-Learning on the Retention of FirstYear Students to Second Year. Michigan Journal of Community Service Learning 16 (2), 38-49.

25. Butin, D. W. 2006. The Limits of Service-Learning in Higher Education. The Review of Higher Education, 29 (4), 473-498.

26. Calderón, J. Z. (Ed.). Race, Poverty, and Social Justice: Multidisciplinary Perspectives through Service Learning. Stylus Publishing, LLC. Proceedings of the ASEE Annual Conference and Exposition, Honolulu, Hawaii, June 2007.

27. Mitchell, T. D. 2007. Critical Service-Learning as Social Justice Education: A Case Study of the Citizen Scholars Program. Equity and Excellence in Education, 40(2), 101-112.

28. Oakes, W. 2009. Creating Effective and Efficient Learning Experiences While Addressing the Needs of the Poor: An Overview of Service-Learning in Engineering Education. Proceedings of the ASEE Annual Conference and Exposition, Austin, Texas, June 2009.

29. Lord, S. M., Cashman, E. M., Eschenbach, E. A., \& Waller, A. A. Feminism and Engineering. Proceedings of the 35th ASEE/IEEE Frontiers in Education Conference, Indianapolis, Indiana, October 2005.

30. Denzin, Norman K. 1997. Interpretive Ethnography: Ethnographic Practices for the $21^{\text {st }}$ Century. Thousand Oaks, CA: Sage Publications.

31. Kemmis, S. \& McTaggart, R. 2005. Participatory Action Research, in The Sage Handbook of Qualitative Research, $3^{\text {rd }}$ Edition, N. K. Denzin \& Y. S. Lincoln (Eds.), Thousand Oaks: California: Sage Publications, 559-603. 


\section{Appendix A - Biographical Sketches}

J. Foster Sawyer: In his role as PI, Sawyer hires faculty participants, assessment coordinators, and student participants and mentors. Sawyer is integrally involved in designing the summer program and research activities for student participants within OSSPEEC. His primary research interests are geologic mapping and groundwater hydrology of the PRR with implications, among others, for greater understanding of the hydrology of the PRR and the timing of geologic events that formed the Black Hills and adjacent areas. Sawyer also performs outreach for the OSSPEEC program, speaking to Native American high school groups and organizing promotional booths at Native American functions in western South Dakota.

Jennifer L. Benning: In 2012, Benning co-taught the Introduction to Engineering summer course offered through OLC. Through her role in OSSPEEC, she integrated into OSSPEEC externally-funded student collaborators and faculty through an EPA funded Environmental Education grant, "Education for the Protection of Water Resources on the Pine Ridge Indian Reservation, South Dakota" and a Housing and Urban Development (HUD) -funded sub-award (through University of Colorado, Boulder) to SDSMT, "Sustainable Construction in Indian Country Small Grant Program, Designing for People and Place: Sustainable \& Affordable Housing for the Pine Ridge Indian Reservation,” using these synergistic programs towards capacity building at OLC and on PRR.

Benning also worked with OSSPEEC students on various service-learning projects. They include surface water quality monitoring, integrating OSSPEEC students into efforts by the Oglala Sioux Tribe Environmental Protection Program (OSTEPP) to promote water resource protection; indoor air quality, energy, and climate monitoring to support sustainable housing research and community development in support of efforts by the Native American Sustainable Housing Initiative (NASHI) (centered at the University of Colorado, Boulder) and the Thunder Valley Community Development Corporation (TVCDC); and advising the design for sustainable food production on PRR.

Damon R. Fick: Fick coordinated the creation of a construction materials laboratory in OLC's Math and Science Building in 2012 with help from summer student interns in OSSPEEC. He helped supervise the purchase and delivery of a load frame and test equipment for concrete materials from SDSMT to OLC. OSSPEEC used the equipment to deliver the laboratory component of a new course, Engineering 202, Construction Materials. As part of the course, he administered certification exams from the American Concrete Institute.

Fick also helped to incorporate a sustainable housing development on the PRR into the Civil Engineering Capstone Design course at SDSMT. The project is a collaboration between the NASHI at University of Colorado, Boulder, and the TVCDC on PRR. His first advisee in OSSPEEC completed this capstone course and graduated with a BS degree in Civil Engineering from SDSMT in 2013. 